\title{
Genetic analysis of the GcvA binding site in the gcvA control region
}

\author{
Alissa D. Jourdan and George V. Stauffer \\ Author for correspondence: George V. Stauffer. Tel: +1 319335 7791. Fax: +1 3193359006. \\ e-mail : george-stauffer@uiowa.edu
}

Department of Microbiology, The University of lowa, lowa City, IA 52242, USA

\begin{abstract}
The GcvA protein both activates and represses the gcv operon and negatively regulates its own transcription. GcvA binds to three sites in the gcv control region and to one site in the gcva control region; each of these binding sites contains the conserved 5 bp DNA sequence 5'-CTAAT-3'. This report describes the role this DNA sequence plays in autoregulation and expression of gcvA. Through single base-pair mutations, the importance of three of these five basepairs in the autoregulation of gcvA expression is shown. Two of the gcvA control region mutations described cause a gcvA:: lacz fusion to be overexpressed at 9-24 times the wild-type level. The increase in expression is due in part to a complete loss of autoregulation and in part to a GcvAindependent mechanism. One of the mutants was shown by Western blot analysis to increase the intracellular concentration of GcvA. This high level of gcvA expression subsequently causes the loss of purine-mediated repression of a gcvT::lacz fusion. However, overexpression of gcvR re-established purinemediated repression of the gcvT: lacZ fusion, supporting the model for gcv regulation that suggests the need for a relatively constant GcvA to GcvR ratio for appropriate regulation of gcv expression in response to glycine and purine availability.
\end{abstract}

Keywords: $g c v A, G c v A$, glycine cleavage, autoregulation, DNA binding site mutations

\section{INTRODUCTION}

The glycine cleavage (GCV) enzyme system in Escherichia coli catalyses the oxidative cleavage of glycine to $\mathrm{CO}_{2}$ and $\mathrm{NH}_{3}$, and the transfer a $\mathrm{C}-1$ methylene unit to tetrahydrofolate (Kikuchi, 1973) (Fig. 1). The resulting 5,10-methylenetetrahydrofolate is used as a $\mathrm{C}-1$ donor in the biosynthesis of purines, methionine, thymine and other cellular components (Mudd \& Cantoni, 1964). In E. coli, three of the proteins of the GCV enzyme complex are encoded by the gcvTHP operon which maps at $62.5 \mathrm{~min}$ on the chromosome (Plamann et al., 1983; Stauffer et al., 1994). The fourth protein, encoded by $l p d$, is not a part of the $g c v$ operon and maps at $2.5 \mathrm{~min}$ (Steiert et al., 1990).

Regulation of the gcv operon is complex and involves at least four proteins. PurR, a global regulator in E. coli involved in negative regulation of many purine and pyrimidine de novo biosynthesis genes (Kilstrup et al.,

Abbreviations: GCV, glycine cleavage; GM, glucose minimal; GMS, gel mobility shift; $L M$, lactose minimal; Lrp, leucine-responsive regulatory protein; TPEG, phenylethyl- $\beta$-D-thiogalactoside; wt, wild-type.
1989; Rolfes \& Zalkin, 1988), also represses gcv expression twofold in the presence of exogenous purines. In vitro studies have shown that PurR binds the $g c v$ control region at a site overlapping the transcriptional start site of $g c v T$, the first gene of the $g c v$ operon, and presumably interferes with transcription initiation by RNA polymerase (Wilson et al., 1993a).

GcvR is also required for repression of $g c v$ (Ghrist \& Stauffer, 1995). Mutations in $g c v R$ result in high constitutive expression of a gcvT::lacZ fusion and overexpression of $g c v R$ results in superrepression of the fusion. Data suggest that repression is mediated through the GcvA protein (Ghrist \& Stauffer, 1995). GcvR alone does not bind to the $g c v$ promoter (A. Ghrist \& G. Stauffer, unpublished data) and whether it is directly or indirectly involved in the repression mechanism has not been determined.

The leucine-responsive regulatory protein (Lrp) is another global regulator in $E$. coli and has been shown to activate or repress many genes involved in amino acid metabolism (Calvo \& Matthews, 1994; Newman et al., 1992). An $\operatorname{lr} p$ mutant containing a gcv $T$ :: lacZ fusion shows low, uninducible $\beta$-galactosidase synthesis (Lin et 


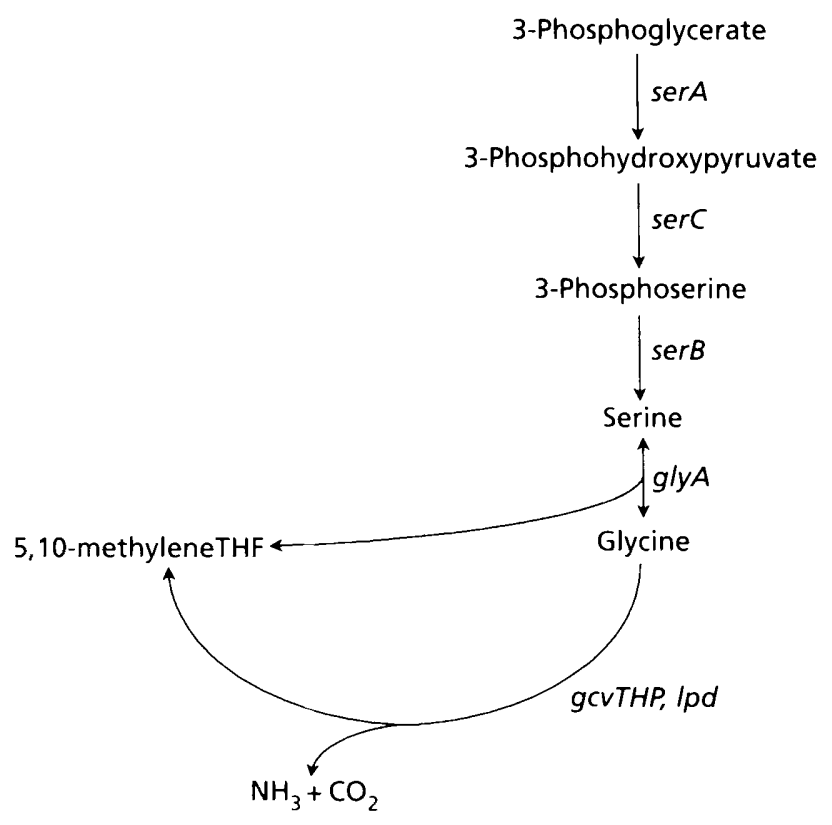

Fig. 1. The serine-glycine pathway in $E$. coli. The genes and the enzymes encoded are as follows: serA, 3-phosphoglycerate dehydrogenase; serC, 3-phosphoserine aminotransferase; ser $B$, 3-phosphoserine phosphatase; glyA, serine hydroxymethyltransferase; lpd, lipoamide dehydrogenase; $g c v$, glycine cleavage enzyme system. THF, tetrahydrofolate.

al., 1992; Stauffer \& Stauffer, 1994). In vitro studies identified multiple Lrp binding sites in the $g c v$ control region from base -229 to -92 relative to the transcription initiation site (Stauffer \& Stauffer, 1994). Lrp appears to play primarily a structural role in $g c v$ regulation, bending the DNA (Stauffer \& Stauffer, 1999).

GcvA, a member of the LysR family of transcriptional regulators (Schell, 1993), plays a dual role in $g c v$ regulation by mediating a fivefold, PurR-independent repression of $\mathrm{gcl}$ expression in the presence of purines and a six- to sevenfold activation in the presence of glycine (Wilson et al., 1993a, b). GcvA binds to three sites in the gc $v^{\prime}$ control region from base -271 to -242 (site 3), from -242 to -214 (site 2) and from -69 to -34 (site 1) relative to the transcription initiation site (Wilson et al., 1995). All three sites are required for GcvA-mediated repression, but only the upstream sites 2 and 3 are required for GovA-mediated activation (Wilson et al., 1995). GovA also binds to a site in the gcu'A control region from base -28 to +20 relative to the gcu'A transcription initiation site, negatively regulating its own expression over an approximately threefold range (Wilson \& Stauffer, 1994). A comparison of these four GcvA binding sites revealed a conserved 5 bp DNA sequence, 5'-CTAAT-3', shown to be important for GcvA binding (Wilson et al., 1995) (Fig. 2a). Overexpression of $g c v$ A results in constitutive expression of a gco'T: : lac Z fusion in the absence of exogenous glycine and in the presence of exogenous purines (Ghrist \& Stauffer, 1995), and thus it appears critical that GcvA levels are maintained within a narrow range for the cell to respond appropriately to a glycine-inducing or purine-repressing signal. A model was previously proposed to explain how GcvA and GcvR might interact to regulate $g c v$ expression, where GcvA homocomplexes function as activators and GcvA-GcvR heterocomplexes function as repressors (Ghrist \& Stauffer, 1995; Wilson \& Stauffer, 1994). This model proposes that the amount of each type of complex formed is likely to be due to the level of the possible coregulators (glycine and purines). High glycine levels would favour activator formation and high purine levels would favour repressor formation. This model also predicts that artificially raising the levels of either GcvA or GcvR would favour the formation of either activator or repressor complexes, respectively.

To define domains of the GcvA protein involved in activation and repression, a genetic selection was designed to screen for mutations in $g c v A$ that produce proteins able to activate but unable to repress the $g c v$ operon. One of the mutations isolated, however, was in the $g c v A$ control region rather than in the structural gene and altered gcvA expression and subsequently gcv $T$ : : lac Z expression. The results are consistent with the model proposed above to explain how GcvA is involved in accomplishing activation and repression of the $g c v$ operon based on GcvA being maintained at a relatively constant ratio with the GcvR protein.

\section{METHODS}

Strains and plasmids. The genotypes of strains and plasmids used in this study are listed in Table 1. All are laboratory strains or were constructed during this investigation.

Media. The minimal growth medium used was Vogel \& Bonner (1956) minimal salts supplemented with $0.4 \%$ glucose (GM) or lactose (LM) and appropriate amino acids and antibiotics as needed. The complex medium used was LuriaBertani broth (LB) (Miller, 1992). Supplements were added at the following concentrations: phenylalanine, $50 \mu \mathrm{g} \mathrm{ml} \mathrm{m}^{-1}$; phenylethyl- $\beta$-D-thiogalactoside (TPEG), $2 \mathrm{mM}$; inosine,

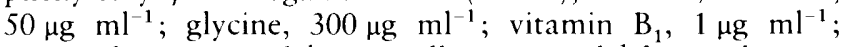
tetracycline, $10 \mu \mathrm{g} \mathrm{ml}^{-1}$; ampicillin, $50 \mu \mathrm{g} \mathrm{m}^{-1}$ for single-copy plasmids and $100 \mu \mathrm{g} \mathrm{ml}^{-1}$ for multicopy plasmids. Minimal medium was supplemented with phenylalanine and vitamin $B_{1}$ because all of the strains used in this study contain pheA905 and thi mutations.

Enzyme assays. $\beta$-Galactosidase assays were performed as described by Miller (1992). All results are the means of two or more assays, with each sample done in triplicate. Protein concentrations were determined by the method of Lowry.

DNA manipulation. Isolation of plasmid DNA, restriction digestions, ligations, DNA sequencing and plasmid transformations were performed as described by Sambrook et al. (1989).

PCR mutagenesis and site-directed mutagenesis. Random mutagenesis of $g c v A$ was performed using the PCR mutagenesis protocol (Zhou et al., 1991). The upstream primer was complementary to the DNA template upstream of the gcv A gene (which retains its own promoter) and a unique EcoRI site, and the downstream primer was complementary to the DNA template distal to the gcvA gene and a unique HindIII site. Several independently mutagenized PCR products were 
Table 1. E. coli K-12 strains and plasmids used in this study

\begin{tabular}{|c|c|c|}
\hline Strain or plasmid & Relevant genotype & Source or reference \\
\hline \multicolumn{3}{|l|}{ Strain } \\
\hline GS162† & $w t$ & This laboratory \\
\hline GS973† & $g c v A 1$ igcvT::lacZ & This laboratory \\
\hline GS986† & gcvA1 purR::Tn10 igcvT::lacZ & This laboratory \\
\hline GS998† & gcvA1 & This laboratory \\
\hline GS1039† & gcvA1 serA25 purR ::Tn10 ìgcvT::lacZ & This laboratory \\
\hline \multicolumn{3}{|l|}{ Plasmids } \\
\hline pMC1403 & lac fusion vector & Casadaban et al. (1980) \\
\hline pGS272 & $\begin{array}{l}\text { pACYC177 derivative, } S m a \text { I site converted to } \\
\text { EcoRI site in kan gene, } \mathrm{Kn}^{\mathrm{s}} \mathrm{Ap}^{\mathrm{r}}\end{array}$ & This laboratory \\
\hline pGS311 & $\begin{array}{l}\text { Single-copy plasmid, } \mathrm{Ap}^{\mathrm{r}} \text {, derived from plasmid } \\
\text { pDF41 } \neq\end{array}$ & This laboratory \\
\hline pGS334 & $\begin{array}{l}1 \mathrm{~kb} \text { EcoRI-HindIII } g c \nu R \text { fragment in pBR322, } \\
\mathrm{Ap}^{\mathrm{r}} T \mathrm{c}^{\mathrm{r}}\end{array}$ & This laboratory \\
\hline pGS335 & $\begin{array}{l}1.3 \mathrm{~kb} \text { EcoRl-HindllI gcvA fragment in pGS272, } \\
\mathrm{Ap}^{\mathrm{r}}\end{array}$ & This study \\
\hline pGS341 & $\begin{array}{l}1.3 \mathrm{~kb} \text { EcoRI-HindIII gcvA fragment from } \\
\text { pGS335 in pGS311, Ap }\end{array}$ & This study \\
\hline pGS383 & EcoRI to Scal deletion in pGS334, $\mathrm{Ap}^{\mathrm{s}} \mathrm{Tc}^{\mathrm{r}}$ & This laboratory \\
\hline pGS468 & $\begin{array}{l}1.3 \mathrm{~kb} \text { EcoRI-HindIII } g c \nu A+13 \mathrm{~A} \text { fragment } \\
(\mathrm{T} \text { to A base change at }+13) \text { in pGS311, } \mathrm{Ap}^{\mathrm{r}}\end{array}$ & This study \\
\hline pGS469 & $\begin{array}{l}1 \cdot 3 \mathrm{~kb} \text { EcoRI-HindIII } g c \nu A+15 \mathrm{G} \text { fragment } \\
(\mathrm{A} \text { to } \mathrm{G} \text { base change at }+15) \text { in pGS311, Ap }\end{array}$ & This study \\
\hline pGS470 & $\begin{array}{l}1.3 \mathrm{~kb} \text { EcoRI-HindIII gcvA }+16 \mathrm{~A} \text { fragment } \\
(\mathrm{T} \text { to A base change at }+16) \text { in } \mathrm{pGS} 311, \mathrm{Ap}^{\mathrm{r}}\end{array}$ & This study \\
\hline
\end{tabular}

\footnotetext{
*Ap, ampicillin; Kn, kanamycin; Tc, tetracycline.

† These strains also carry thi, pheA905, $\Delta$ lacU169, araD129 and rpsL150 mutations.

$\ddagger$ Plasmid pDF41 (Kahn et al., 1979) was obtained from S. R. Kushner, University of Georgia, USA.
}

collected, digested with EcoRI and HindIII, purified from a low-melting-point agarose gel, ligated into the EcoRI-HindIII sites of the single-copy plasmid pGS311 and transformed into the $g c v A 1$ strain GS1039 lysogenized with a $\lambda g c v T:: l a c Z$ translational fusion phage.

Site-directed mutagenesis of $g c v A$ was performed using a PCR 'megaprimer' mutagenesis protocol (Sarkar \& Sommer, 1990). Changes were introduced through downstream primers complementary to gcvA except at the position of the desired base change. PCR products were generated using a primer upstream of a unique EcoRI site and complementary to vector DNA outside of the $g c v A$ insert. These PCR products were then used as the upstream megaprimers in another round of PCR synthesis against the same DNA template. The downstream primer was complementary to an internal segment of $g c v A$ distal to the mutagenic primer and an internal MluI site. PCR products were cut with $E c o R I$ and $M l u I$, purified from a low-melting-point agarose gel and ligated into EcoRI-MluIdigested plasmid pGS341. The resulting plasmids (pGS468, pGS470 and pGS471) each contained specific base mutations that were verified by the complete DNA sequence analysis of each EcoRI-MluI fragment.

Construction of lysogens. Plasmids pGS468, pGS469 and pGS470 were digested with EcoRI and EcoRV and the 519 bp fragment from each digest, containing the $303 \mathrm{bp}$ region upstream of $g c v A$ and the first 72 codons of $g c v A$, were isolated from a low-melting-point agarose gel and ligated into the EcoRI-SmaI sites of plasmid pMC1403 (Casadaban et al.,
1980), forming an in-frame translational fusion to lac $Z$. The resulting plasmids were sequenced across the fusion junction, confirming that the correct reading frame had been maintained. Each plasmid was cut at a unique Sall site at the end of the lacZYA segment, the ends filled in using T4 DNA polymerase and EcoRI linkers added using T4 DNA ligase. The plasmids were then digested with EcoRI and a $6686 \mathrm{bp}$ EcoRI-EcoRI fragment, containing each mutant gcvA control region, the first 72 codons of $g c v A$ and lacZYA, was isolated and cloned into the EcoRI site of $\lambda$ gt 2 (Panasenko et al., 1977). In the resulting phages $\beta$-galactosidase synthesis is under control of the gcvA control region. The phages were used to lysogenize appropriate strains as described previously (Urbanowski \& Stauffer, 1986). The lysogens were tested for the presence of a single copy of $i$ phage by infection with $\lambda c 190 c 17$ (Shimada et al., 1972). The effect of each of the mutations in the $g c v A$ control region on $g c v A$ expression was measured by $\beta$-galactosidase assay. As controls, a wild-type (wt) $\lambda g c \nu A:$ : lac Z fusion constructed previously in an identical manner (Wilson \& Stauffer, 1994) was used to lysogenize appropriate strains and $\beta$-galactosidase activity was measured.

Gel mobility shift assays. Gel mobility shift (GMS) assays were performed based on the methods of Fried \& Crothers (1981) and Garner \& Revzin (1981). A 519 bp EcoRI-BamHI fragment from each of the $g c \nu A::$ lacZ fusion plasmids, containing $303 \mathrm{bp}$ upstream of the $g c v A$ transcription start site and the first 72 codons of $g c v A$, was ${ }^{32} \mathrm{P}$-labelled at the unique EcoRI site using T4 polynucleotide kinase (Sambrook et al., 
1989). The assay (20 $\mu$ l final volume) was performed by incubating each labelled DNA fragment in DNA binding buffer (.5 mM Tris/ $\mathrm{mCl}, \mathrm{pH} 7 \cdot 5,25 \mathrm{mM} \mathrm{KCl}, 0.5 \mathrm{mM}$ EDTA, $2.5 \%$ glycerol, $0.5 \mathrm{mM}$ DTT) plus $125 \mu \mathrm{g} \mathrm{BSA} \mathrm{ml}{ }^{1}$ for $5 \mathrm{~min}$ at $37^{\circ} \mathrm{C}$ and then adding $2 \mu \mathrm{l}$ volumes of twofold serial dilutions of (icvA (Jourdan \& Stauffer, 1998) diluted in DNA binding buffer plus $125 \mu \mathrm{g} \mathrm{BSA} \mathrm{ml}{ }^{1}$. Incubation was continued at $37^{\circ} \mathrm{C}$ for $15 \mathrm{~min}, 2 \mu \mathrm{l}$ loading dye $(0 \cdot 1 \%$ xylene cyanol, $50 \%$ glycerol $)$ was added and the samples were loaded and run on a $5 \%$ polyacrylamide $/ 3 \%$ glycine gel.

Western blot analysis. Cells were grown in $1 \mathrm{ml}$ GM plus ampicillin $\left(50 \mu \mathrm{g} \mathrm{ml}{ }^{1}\right)$ overnight at $30^{\circ} \mathrm{C}$, then diluted into $50 \mathrm{ml}$ CM plus ampicillin and incubated at $30^{\circ} \mathrm{C}$ until midexponential phase $\left.(\mathrm{OD})_{600} \sim 0 \cdot 5\right)$. Cells were collected at $4{ }^{\circ} \mathrm{C}$ by centrifugation and the cell pellet was frozen overnight at $-70{ }^{\circ} \mathrm{C}$. The cell pellet was resuspended in $2 \mathrm{ml}$ sodium phosphate buffer $(50 \mathrm{mM}$ sodium phosphate, $500 \mathrm{mM} \mathrm{NaCl}$ ) and sonicated on ice until viscous and clear. Cytoplasmic and membrane fractions were separated by centrifugation and the supernatant was brought to $3.3 \%$ ammonium sulfate saturation. Precipitated protein was collected by centrifugation and resuspended in $120 \mu \mathrm{l}$ TEG buffer $(50 \mathrm{mM}$ Tris $/ \mathrm{HCl}$, pH 7.9, $0.5 \mathrm{mM}$ EDTA, $5 \%$ glycerol). Protein concentration was determined using the Bio-Rad Protein Assay Kit II. Proteins were electrophoresed by SIDS-PACE, followed by transfer onto a nitrocellulose membrane as described by Sambrook et al., (1989). The blotted proteins were reacted with primary antibody (Tetra-His Antibody; Qiagen) diluted according to the manufacturer's suggestions, followed by reaction with secondary antibody [alkaline-phosphataseconjugated polyclonal sheep anti-mouse $\operatorname{Ig} G(\mathrm{H}+\mathrm{L})$; ICN Biomedicals $\mid$ diluted according to the manufacturer's directions. Colorimetric detection was done according to the Qiagen protocol for Western blot immunodetection.

\section{RESULTS AND DISCUSSION}

\section{Isolation of a gcvA mutant affecting purine repression of $g \subset v$}

It was shown previously that GcvA functions to both activate and repress a gco'T::lac Z fusion (Wilson et al., $1993 \mathrm{a}, \mathrm{b})$. To define amino acids in GcvA important for iss repressor function, we attempted to isolate $\mathrm{gcv} A$ mutants that encoded proteins that could no longer repress gcv $T::$ lac $Z$ expression in the presence of purines but could activate expression in the presence of glycine. The following selection strategy was used to obtain such gcu'A mutants. Strain GS1039 is a serA gcvA double mutant that requires serine for growth. This double mutant cannot grow on a GM plate supplemented with only glycine because in the absence of GovA there are insufficient $\mathrm{C}-1$ units available from the GCV enzyme system for the conversion of glycine into serine via the serine hydroxymethyltransferase reaction (Fig. 1). If wt $g c v^{\prime} A$ is supplied in trans, growth on a GM plate supplemented with glycine occurs because GcvA, in the presence of glycine, activates expression of the GCV enzyme system resulting in cleavage of glycine and the production of C-1 units. Although strain GS1039 carries a gcv $T$ : : lac $Z$ translational gene fusion on an integrated $i$ phage, when wt gcvA is supplied in trans this lysogen cannot grow on a LM plate supplemented with serine, inosine and TPEG (a competitive inhibitor of $\beta$ - galactosidase; Miller, 1992) because GcvA, in the presence of inosine, represses the fusion resulting in insufficient $\beta$-galactosidase expression to support growth on lactose. The presence of TPEG increases the stringency of the selective media. Lysogen GS1039 was transformed with a single-copy plasmid pool carrying PCR-induced random base changes in gcv A (including the promoter region) and plated on LB agar (appropriate antibiotics were added to all selection media). Colonies were patched to LM plates supplemented with serine, inosine and TPEG, and to GM plates supplemented with glycine. Our selection assumed that cells containing mutations in $g c v A$ that alter the repressor function but not the activator function of GcvA would grow on both of the scoring media. One of about 1000 transformants tested was capable of growth on both of the scoring media. The transformant was single-colony-purified and the plasmid carrying the putative $g c v A$ repressor mutation was isolated.

To determine the effects of the gcvA repressor mutation on $g c v T:: l a c Z$ expression, the plasmid carrying the putative $g c v A$ mutation was used to transform the gcvA1 mutant strain GS986 which was lysogenized with a $\lambda g c v T:: l a c Z$ fusion. Repression of the $g c v T:: l a c Z$ fusion in strain GS986 is mediated through the plasmidborne $g c v$ A-encoded protein and not PurR. As a control, lysogen GS986 was also transformed with plasmid pGS341 which carries the wt gcvA gene. The transformants were grown in GM medium or GM medium supplemented with either glycine or inosine and assayed for $\beta$-galactosidase activity. GS986 transformed with the plasmid carrying the repressor mutation in gcvA displayed normal induction of $g c v T:: \operatorname{lac} Z$ expression when grown in the presence of glycine, but in the presence of inosine there was an approximately twofold increase in $g c v T:: l a c Z$ expression compared with that of the control strain GS986(pGS341) (data not shown). These results suggest that the plasmid carries the relevant $g c v A$ repressor mutation allowing growth on the scoring plates.

The mutant $g c v A$ gene from the plasmid was sequenced and a single base change from $A$ to $G$ at position +15 relative to the transcriptional start site was identified and designated $+15 \mathrm{G}$ (Fig. 2b). This A to $\mathrm{G}$ transition occurs within the conserved 5 bp $5^{\prime}$-CTAAT- 3 ' sequence common to all four known GcvA binding sites and is believed to be involved in binding of GevA to DNA (Wilson et al., 1995) (Fig. 2). The plasmid carrying the $+15 \mathrm{G} \mathrm{gcvA}$ mutation was designated pGS469.

\section{The $+15 \mathrm{G}$ mutation in the GcvA binding site causes overexpression of gcvA: :lacZ}

Overexpression of wt gcvA from the tac promoter results in a relief of purine-mediated repression of a gcvT:: lacZ fusion (Ghrist \& Stauffer, 1995). Because the $+15 \mathrm{G}$ mutation also resulted in a relief of purinemediated repression of a $g c v T:: \operatorname{lac} Z$ fusion and lies in the putative autoregulatory GcrA consensus binding site, it was hypothesized that this mutant might over- 
(a)

\section{gcv Site 1}

gcv Site 2

gcv Site 3

gcvA

5 '-AGCTCAACGGACAATTTATAATGGCTCAGATTAAAAAAACTAATAGGTT- 3 '

(b)

s'-CACTATAGGTATTTGCTGGTAGAAGCTCAACGGACAATTTATAATGGCTCAGATTAAAAAACTAATAGGTTACATAGT

SD

5'-CATAAGCTAATGTGATGATCAATTTTACCTTATGGT-3'

$s^{\prime}$-CGTTTTCGCATTATATTTTCTAATGCCAT-3'

$5^{\prime}$-CCTCATTTGAAATAAACTAATTTCACCTC-3'

GT GATCTAATTGTTAAATTCATTTAACATCAAAGTTTAATA GCCATG-TCT-AAA-3'
Fig. 2. (a) Alignment of partial sequences of $g \subset v$ and gCvA DNAs protected by GcvA from DNase I digestion. The conserved $5 \mathrm{bp} 5^{\prime}-$ CTAAT-3' DNA sequence is in bold. (b) DNA sequence of the gcvA control region. The putative -10 and -35 promoter regions are indicated above the sequence. The transcription initiation site is underlined and indicated by +1 . The conserved 5 bp 5'-CTAAT-3' DNA sequence is in bold. The base changes isolated by genetic selection or by megaprimer mutagenesis are indicated above the sequence. The Shine-Dalgarno (SD) sequence is overlined. The first codon of GcvA is underlined and in bold. The region of the gcvA promoter protected by GcvA from DNase I digestion (Wilson et al., 1995) is underlined and in bold.
Table 2. Effect of gcvA control region mutations on gcvA::lacZ expression

Cells were grown in GM medium and assayed for $\beta$-galactosidase activity.

\begin{tabular}{|lcc|}
\hline \multirow{g}{*}{$\boldsymbol{A} \boldsymbol{A}:$ lacZ fusion $^{*}$} & $\boldsymbol{\beta}$-Galactosidase activity (Miller units) \\
\cline { 2 - 3 } & GS162 (wt) & GS998 (gcvAl) \\
\hline wt & $3 \pm 1$ & $9 \pm 0 \cdot 5$ \\
$+13 \mathrm{~A}$ & $66 \pm 2$ & $70 \pm 2$ \\
$+15 \mathrm{G}$ & $26 \pm 2$ & $35 \pm 2 \cdot 5$ \\
$+16 \mathrm{~A}$ & $2 \cdot 3 \pm 0 \cdot 1$ & $1 \cdot 4 \pm 0 \cdot 2$ \\
\hline
\end{tabular}

"Denotes the igcvA::lacZ wt and mutant phages used to lysogenize strains GS998 and GS162.

express GcvA. To examine this possibility, a lacZ translational fusion was constructed where $\beta$-galactosidase is under control of the $+15 \mathrm{G}$ mutant control region (see Methods). The fusion was cloned into $\lambda \mathrm{gt} 2$ and the phage designated $\lambda g c v A:: l a c Z+15 \mathrm{G}$. Phage $\lambda g c v A:: \operatorname{lac} Z+15 \mathrm{G}$ was then used to lysogenize the wt strain GS162 and the gcvA1 mutant strain GS998. As controls, a wt $\lambda g c \nu A$ : : lac $Z$ phage was used to lysogenize the same strains. The lysogens were grown in GM medium and assayed for $\beta$-galactosidase activity. As reported previously (Wilson \& Stauffer, 1994), expression of the wt $\lambda g c v A:: l a c Z$ fusion is autoregulated about threefold in the wt strain GS162 compared to the gcvA1 strain GS998 (Table 2). However, the igcvA : : lac $Z+15 \mathrm{G}$ fusion did not show a significant difference in $\beta$-galactosidase levels in the wt strain compared to the gcvA1 strain (Table 2), suggesting that the $+15 \mathrm{G}$ mutation prevents GcvA from autoregulating $\lambda g c v A:: l a c Z+15 \mathrm{G}$. Furthermore, in the gcvA1 strain GS998, $\beta$-galactosidase synthesis from the igcvA : : lac Z +15G fusion increased about 3.9-fold com- pared to the wt fusion, indicating that the $+15 \mathrm{G}$ mutation caused an additional GcvA-independent increase in $g c v A:$ : lac $Z$ expression.

\section{Effects of additional base changes in the GcvA binding site on gcvA::lacZ expression}

To determine if other bases in the 5'-CTAAT- $3^{\prime}$ sequence of the GcvA binding site are important in autoregulation at the gcvA promoter, both bases +13 and +16 were each independently changed from $\mathrm{T}$ to $\mathrm{A}$ using the megaprimer PCR mutagenesis protocol (see Methods) (Fig. 2b). Each base change was translationally fused to the lacZYA reporter genes such that expression of these genes is under control of the $g c v A$ promoter regions containing the altered GcvA binding sites. The fusions were cloned into igt 2 and the resulting phages, designated $\lambda g c v A:: \operatorname{lac} Z+13 \mathrm{~A}$ and $\lambda g c v A:: l a c Z+16 \mathrm{~A}$, were used to lysogenize wt strain GS162 and the $g c v A 1$ mutant strain GS998. The lysogens were grown in GM medium and assayed for $\beta$ galactosidase activity. The $\lambda g c v A:: l a c Z+13 \mathrm{~A}$ fusion showed no significant difference in $\beta$-galactosidase levels in the wt strain GS162 compared to the gcvA1 strain GS998 (Table 2), suggesting the $+13 \mathrm{~A}$ base change prevented GcvA-mediated autoregulation, similar to the $+15 \mathrm{G}$ mutation. In addition, in strain GS998 the $+13 \mathrm{~A}$ base change resulted in a $7 \cdot 8$-fold GcvA-independent increase in $g c \nu A::$ lac $Z$ expression. The $+16 \mathrm{~A}$ mutation in the $g c v A$ control region also resulted in the loss of autoregulation of $g c v A:: \operatorname{lac} Z$ expression similar to the $+13 \mathrm{~A}$ and $+15 \mathrm{G}$ mutants (Table 2). However, uniike the $+13 \mathrm{~A}$ and $+15 \mathrm{G}$ base changes, the $+16 \mathrm{~A}$ mutation showed a GcvA-independent decrease in gcvA::lacZ expression (Table 2). Why expression of gcvA::lacZ increased with the $+13 \mathrm{~A}$ and $+15 \mathrm{G}$ base changes is unknown, although there are several possible explanations. These changes may have increased the strength of the $g c v A$ promoter, thus increasing transcription initiation. Although changes in the initially transcribed 
(a)

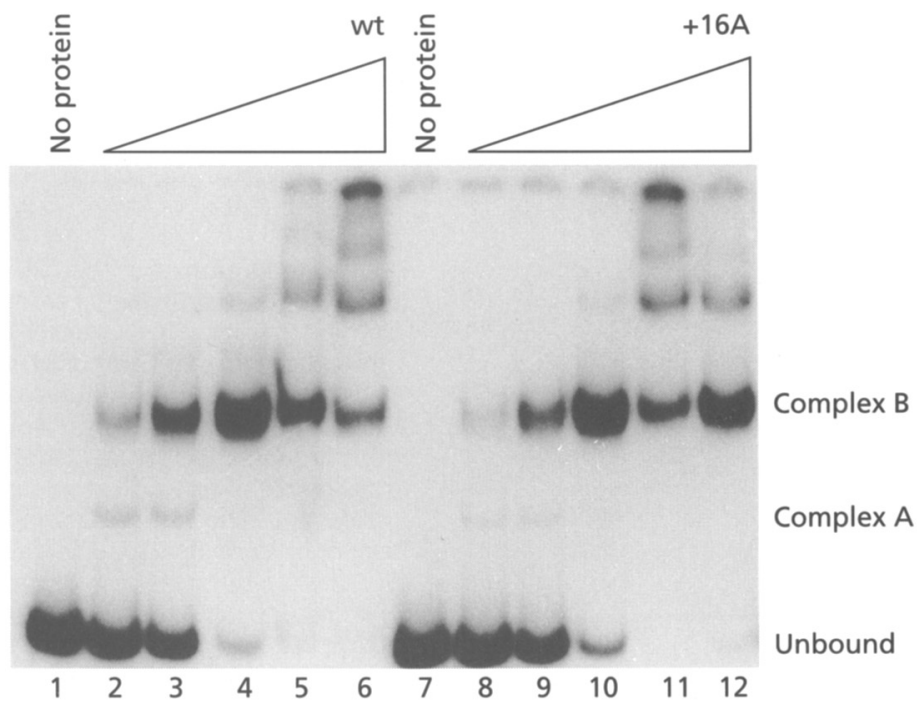

(b)

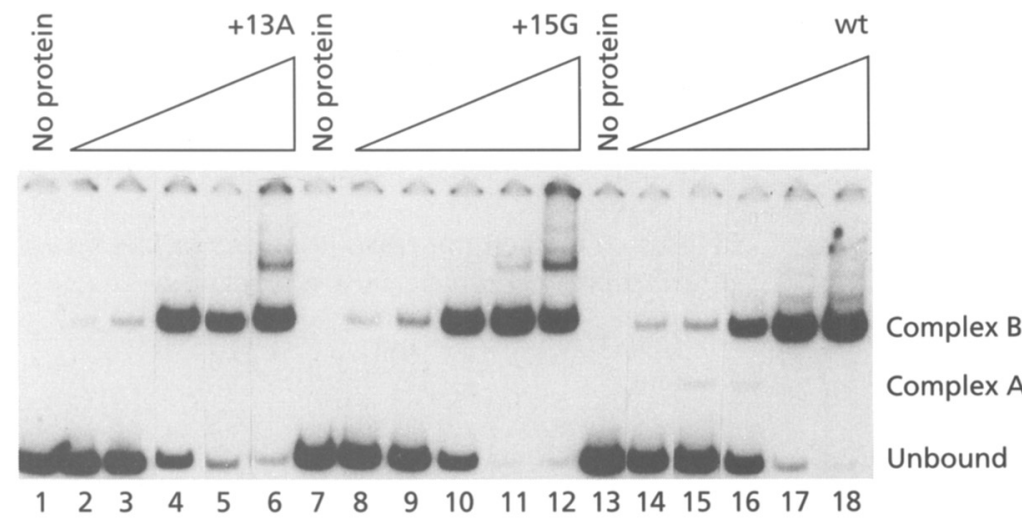

Fig. 3. Gel mobility shift assay for the binding of GcvA to wt and mutant gCVA DNAs. The $519 \mathrm{bp}$ fragments containing the wt and mutant gcvA control regions were incubated with GCvA protein and the samples were run on a $5 \%$ polyacrylamide $3 \%$ glycine gel (see Methods). Each reaction was performed in a $20 \mu \mathrm{l}$ volume. (a) Lanes: 1-6, wt DNA; 7-12, gcvA +16A DNA; 1 and 7, no protein; 2-6 and $7-12,5,10,20,40$ and $80 \mathrm{nM}$ GcvA protein, respectively. (b) Lanes: 1-6, gcvA + 13A DNA; 7-12, gCvA + 15G DNA; 13-18, wt gCvA DNA; 1,7 and 13 , no protein; $2-6,8-12$ and $14-18,5,10,20,40$ and $80 \mathrm{nM}$ Gcva protein, respectively. The unbound DNA fragments are indicated. Complexes $A$ and $B$ are likely to represent GcvA bound to one half and the full $48 \mathrm{bp}$ GcvA target sequence, respectively. region are known to affect promoter strength (Record et al., 1996), it should be noted that the changes reported here are a considerable distance from the +1 transcription initiation site. These changes may have generated a new promoter that is stronger than the wt promoter. However, the base changes do not create a recognizable promoter consensus sequence. Changing these bases may have altered the efficiency at which the mRNA is translated, or may have increased the stability of the mRNA. Finally, there could be an additional $E$. coli protein that regulates $g c^{\prime} A$ expression, or a protein that normally does not recognize the gov A control region DNA but, when this DNA is mutated, now increases ga'A expression. We are developing in vitro assays and in tivo selections that should allow us to determine which of the above possible scenarios is most likely responsible for the altered gov'A expression in these mutants.

\section{Gcva binding to the mutant gcvA control regions}

GMS assiys were performed to determine if the loss of autoregulation observed by changing bases in the GevA binding site were due to an altered hinding affinity of GcvA for DNA (Fig. 3). Purified GicvA protein used in all
GMS assays is given in monomer concentrations (Jourdan \& Stauffer, 1998). At the lower concentrations of protein used in the GMS assay the wt gcvA fragment was shifted to two hands of slower mobility (Fig. 3a, lanes 2-3; rig. 3b, lanes 14-16; complexes $A$ and B). At the higher concentrations of protein used the fragment was shifted to multiple bands of slower mobility (Fig. $3 a$, lanes 4-6; Fig. 3b, lanes 17-18). It should be noted that complex $B$ is the predominant band at any GcvA concentration used in the assay. Previous results from a DNase I footprint analysis of gcvA identified a single target site of about $48 \mathrm{bp}$ (Fig. 2) (Wilson et al., 1995). We believe that complex $A$ and $B$ indicate that the binding region is made up of two target sites and that Geva binding to these two sites is cooperative. However, it is also possible that the two sites have essentially equal affinity for $g c{ }^{\prime} A$. The additional bands of slower mobility at the higher concentrations of GcvA used in the assay are likely to be due to non-specific binding, as DNase I footprint assays did not show protection other than the GovA binding region previously identified (Fig. 2) (data not shown). The $+16 \mathrm{~A}$ fragment had a GMS pattern essentially the same as the wt (Fig. 3a, compare lanes $7-12$ with lanes $1-6$ ). The amount of GcuA protein required to bind and shift the $+13 \mathrm{~A}$ and $+15 \mathrm{G} \mathrm{gcvA}$ 
GcvA binding site for $g c v A$

Table 3. Effects of varying $g c v A$ expression on $g c v T:$ : lacZ expression

All plasmids were assayed in strain GS986. Cells were grown in GM medium with the indicated supplements and assayed for $\beta$-galactosidase activity.

\begin{tabular}{|lcccc|}
\hline Plasmid & $\boldsymbol{g} c \boldsymbol{v} \boldsymbol{A}$ allele & \multicolumn{2}{c|}{$\boldsymbol{\beta}$-Galactosidase activity (Miller units) } \\
& & None & Glycine & Inosine \\
& & & $732 \pm 26$ & $26 \pm 1$ \\
\hline pGS341 & wt $g c v A$ & $157 \pm 10$ & $1148 \pm 46$ & $649 \pm 13$ \\
pGS468 & $g c v A+13 \mathrm{~A}$ & $942 \pm 50$ & $705 \pm 23$ & $54 \pm 3$ \\
pGS469 & $g c v A+15 \mathrm{G}$ & $182 \pm 7$ & $791 \pm 79$ & $34 \pm 2$ \\
pGS470 & $g c v A+16 \mathrm{~A}$ & $187 \pm 11$ & & \\
\hline
\end{tabular}

fragments was essentially the same as the wt fragment (Fig. 3b, compare lanes 1-6 and 7-12 with lanes 13-18), suggesting that the overall affinity of GcvA for the mutant DNAs was not significantly altered. However, complex A present in the GMS pattern of the wt and $+16 \mathrm{~A} g c \nu A$ DNA, was not observed for the $+13 \mathrm{~A}$ and $+15 \mathrm{G} g c v A$ DNAs. At the two highest concentrations of protein, there was essentially no difference in the GMS patterns between the $+13 \mathrm{~A}$ and $+15 \mathrm{G}$ mutant and wt $g c v A$ DNAs (Fig. 3b, compare lanes 5-6 and 11-12 with lanes 17-18). A DNase I footprint analysis of the $+13 \mathrm{~A}$ and $+15 \mathrm{G}$ DNAs revealed that despite the slightly altered GMS pattern there was no significant difference in the DNase I protection observed between the mutant $g c v A$ control regions and the wt control region (data not shown). Despite the similarity in the overall affinity of GcvA for the wt and mutant DNAs in vitro, GcvA either does not bind in vivo or when bound to these DNAs in vivo is unable to regulate $g c v A:: l a c Z$ expression. The results also suggest that the $5^{\prime}$-CTAAT3 ' sequence shown to be important for GcvA binding in the $g c v$ control region (Wilson et al., 1995) is not essential for GcvA binding in the gcvA control region.

\section{Modifying the level of gcvA expression affects gcv regulation}

Previous studies have shown that regulation of a $g c v T:: l a c Z$ fusion is sensitive to the level of GcvA in the cell (Ghrist \& Stauffer, 1995). Overexpression of gcvA leads to the loss of purine-mediated repression and constitutive expression of a $g c v T:: l a c Z$ fusion in the absence of exogenously added glycine (Ghrist \& Stauffer, 1995). Each of the mutants described above had either increased or decreased $g c v A:$ :lacZ expression. To determine the effects the altered levels of $g c v A$ expression had on $g c v T:: l a c Z$ expression, plasmids were constructed in which each mutant control region was translationally fused upstream of the $g c v A$ structural gene (see Methods). The plasmids were then transformed into the gcvA1 purR ::Tn10 mutant strain GS986 that was lysogenized with a $\lambda g c v T:: l a c Z$ fusion. The transformants were grown in GM medium and GM medium supplemented with either glycine or inosine and assayed for $\beta$-galactosidase activity. The wt control transformant GS986(pGS341) showed a 4.7-fold glycinemediated induction and a 6-fold purine-mediated repression of the $g c v T$ ::lacZ fusion (Table 3). Transformant GS986(pGS469), carrying the $g c v A+15 G$ mutation which caused an 8.7-fold overexpression of the gcv A : : lac Z fusion (Table 2), resulted in a 2-fold loss of GcvA-mediated repression of the gcv T::lacZ fusion when grown in the presence of inosine (Table 3). The $+15 \mathrm{G}$ base change had no significant effect on gcv $T:: l a c Z$ expression when the lysogen was grown in GM medium or GM medium supplemented with glycine. Transformant GS986(pGS468), carrying the gcvA $+13 \mathrm{~A}$ mutation which caused a 22 -fold overexpression of the gcvA::lacZ fusion (Table 2), resulted in constitutive expression of the $g c v T:: l a c Z$ fusion under all growth conditions (Table 3 ). These results suggest that the ability of the gcv $T:: l a c Z$ fusion to be regulated in response to normal physiological signals for activation and repression was altered by increased levels of GcvA. Transformant GS986(pGS470), carrying the gcvA +16A mutation which had no significant effect on levels of $g c v A$ :: lacZ expression (Table 2), showed essentially normal gcvT::lacZ expression compared to the wt gcvT:: lacZ fusion (Table 3).

\section{The $+13 A$ mutant control region increases intracellular levels of GcvA}

We tested directly whether the $+13 \mathrm{~A}$ base change in the gcvA control region that caused $g c v A:$ : lac $Z$ expression to increase 22-fold resulted in overproduction of the GcvA protein by Western blot analysis. The Tetra-His Antibody (Qiagen) reacts with four histidine residues present in a histidine-tagged protein. A sequence encoding six histidine residues $\left(\mathrm{His}_{6}\right)$ was added to the 3' end of the $g c v A$ gene $\left(g c v A:: \mathrm{His}_{6}\right.$ ) (Jourdan \& Stauffer, 1998). Strain GS986 transformed with single-copy plasmids carrying the wt control region upstream of gcvA:: $\mathrm{His}_{6}$, the $+13 \mathrm{~A}$ control region upstream of gcvA:::His ${ }_{6}$ and the vector only were grown as described, protein prepared and used in Western blot analysis (see Methods). The vector only protein preparation did not react with the Tetra-His Antibody at any 


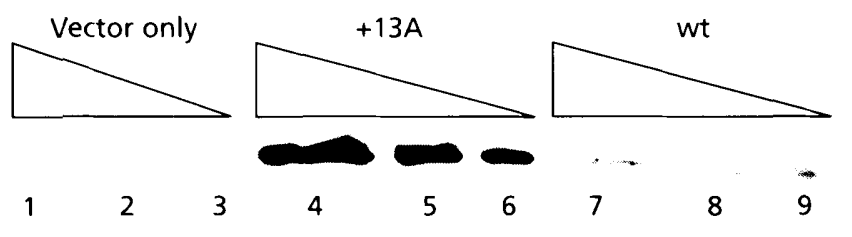

Fig. 4. Western blot analysis of the amount of GcvA expressed from the wt and +13A gcvA control regions. Lanes 1-3, 128, 64 and $32 \mu \mathrm{g}$ crude extract protein, respectively, prepared from vector only transformants; 4-6, 128, 64 and $32 \mu \mathrm{g}$ crude extract protein, respectively, prepared from $+13 A$ transformants; $7-9$, 128,64 and $32 \mu \mathrm{g}$ crude extract protein, respectively, prepared from wt transformants.

of the protein concentrations used (Fig. 4, lanes 1-3). The GevA-His ${ }_{6}$ protein preparation under control of its native promoter gave a weak signal that increased as the protein concentration was increased (Fig. 4, lanes 7-9). The low level of $\mathrm{GcvA}-\mathrm{His}_{6}$ detected corresponds well with the low level of wt $g c v A::$ lac $Z$ expression in a GS162 wt strain (Table 2). The GcvA-His ${ }_{6}$ protein preparation under control of the $+13 \mathrm{~A}$ control region displayed a strong reaction that increased as the amount of total protein increased (Fig. 4, lanes 4-6). The Western analysis agrees well with the igcuA::lac $Z+13 \mathrm{~A}$ expression data (Table 2). Since it was shown previously that overexpression of $g c v A$ from the tac promoter causes a loss of gcv $T::$ lac $Z$ repression (Ghrist \& Stauffer, 1995), the overproduction of the GcvA protein in the $+13 \mathrm{~A}$ mutant could account for the loss of gcv T::lacZ repression observed in cells containing plasmid pGS468 (Table 3).

\section{Overexpression of GcvR in mutant gcvA strains mediates the return of $g c v T:: / a c Z$ regulation}

Overexpression of $g c v R$ results in superrepression of a $g c v T:$ : lac Z fusion and this repression is dependent on a functional gcu'A gene (Ghrist \& Stauffer, 1995). We hypothesized that if the signal for activation and repression of a gcv T:: lac $Z$ fusion is dependent upon the ratio of GevA to GcvR in the cell, then the altered regulation of the $g c v T:: \operatorname{lac} Z$ fusion observed with the $g c v A+13 \mathrm{~A}$ and $g c v A+15 \mathrm{G}$ mutations (Table 3) would be eliminated by overexpressing $g c v R$ in the mutant $g c v A$ backgrounds. To examine this hypothesis, strain GS973, a gcvA1 mutant carrying a igcv T: lacZ fusion, was transformed with plasmids pGS468 and pGS469 carrying the $g c v A+13 \mathrm{~A}$ and $g c \nu A+15 \mathrm{G}$ mutations, respectively. These strains were then transformed with plasmid pGS383, a pBR322 derivative carrying wt $g c v R$, to produce two strains containing plasmids that overproduce both GcvA and GcvR. Two control strains were also constructed by transforming GS973 with plasmid pGS341, the single-copy plasmid carrying wt gcvA, and by transforming GS973 with both plasmids pGS341 and pGS383. The GS973(pGS341) transformant contained one plasmid-borne copy of gcvA and a chromosomal copy of $g c v R$. The GS973(pGS341)(pGS383) transformant contained one plasmid-borne copy of $g c v A$ and multiple copies of $g c v R$. These strains were grown in GM medium and GM medium supplemented with either glycine or inosine and assayed for $\beta$-galactosidase activity. The control strain GS973(pGS341) showed normal glycine-mediated activation and purine-mediated repression (Table 4). When both the single-copy gcvA plasmid pGS341 and the multicopy gcvR plasmid pGS383 were transformed into GS973, superrepression occurred under all growth conditions (Table 4). In the GS973(pGS469)(pGS383) double transformant, where gcvA was overexpressed about $8 \cdot 7$-fold and $g c v R$ was overexpressed about 30 fold [based on the copy number of the vector (Bolivar $e t$ al., 1977) and the observation that $g c v R$ is constitutively expressed (Ghrist \& Stauffer, 1995)], superrepression of gcvT: : lacZ occurred under all growth conditions (Table 4). In the GS973(pGS468)(pGS383) double transformant, where gcvA was overexpressed about 22 -fold and gcvR was overexpressed about 30 -fold, the level of gcvT::lacZ expression was still repressed under all growth conditions. However, there was a significant increase in $\beta$-galactosidase activity in this transformant compared to the strain carrying a single copy of $g c v A$, or in the strain where gcvA was overexpressed only 8.7 fold. In addition, this transformant could mediate a 6.2 fold activation of $g c v T::$ lac $Z$ expression in the presence of glycine (Table 4), although the induced levels were $3 \cdot 7$-fold lower than the control strain with a single copy

Table 4. Effects of overexpressing gcvR on $g \subset v T:: / a c Z$ expression in cells overproducing gcvA

All plasmids were assayed in strain GS973. Cells were grown in GM medium with the indicated supplements and assayed for $\beta$-galactosidase activity.

\begin{tabular}{|lcccc|}
\hline Plasmid & $\begin{array}{c}\text { Relative levels of } \\
\text { GcvA and GcvR }\end{array}$ & \multicolumn{2}{c|}{$\boldsymbol{\beta}$-Galactosidase activity (Miller units) } \\
\cline { 3 - 5 } & & None & Glycine & Inosine \\
\hline pGS341 & $\mathrm{A}^{+}, \mathrm{R}^{+}$ & $163 \pm 28$ & $766 \pm 110$ & $7 \pm 1$ \\
pGS341+pGS383 & $\mathrm{A}^{+}, \mathrm{R}^{+++}$ & $7 \pm 0$ & $13 \pm 1$ & $1 \pm 0$ \\
pGS468+pGS383 & $\mathrm{A}^{++}, \mathrm{R}^{+++}$ & $33 \pm 1$ & $205 \pm 10$ & $3 \pm 0$ \\
pGS469+pGS383 & $\mathrm{A}^{++}, \mathrm{R}^{+++}$ & $5 \pm 1$ & $13 \pm 0$ & $0 \cdot 45 \pm 0 \cdot 1$ \\
\hline
\end{tabular}


of $g c v A$ and $g c v R$. These results indicate that the loss of gcvT: : lac $Z$ repression caused by overexpression of gcvA can be overcome by proportionally overexpressing $g c \nu R$ and suggest that the proper ratio of GcvA and GcvR, rather than their absolute levels, is critical for normal regulation of the $g c v$ operon. We have designed a genetic screen to isolate mutations in the coding region of $g c v A$ that would render the GcvA protein either unable to repress $g c v$ in the presence of inosine or, alternatively, unable to activate $g c v$ in the presence of glycine. One $g c v A$ mutant isolated encodes a protein that no longer responds to GcvR for repression (A. D. Jourdan \& G. V. Stauffer, unpublished data), supporting a model where GcvR and GcvA might interact. Careful analysis of this and additional mutants will provide insight into the mechanisms by which GcvA and GcvR are involved in activating and repressing the $g c v$ operon.

\section{ACKNOWLEDGEMENTS}

This investigation was supported by Public Health Service grant GM26878 from the National Institute of General Medical Sciences.

\section{REFERENCES}

Bolivar, F., Rodriguez, R. L., Greene, P. J., Betlach, M. C., Heyneker, H. L., Boyer, H. W., Crosa, J. H. \& Falkow, S. (1977). Construction and characterization of new cloning vehicles. II. A multipurpose cloning system. Gene 2, 95-113.

Calvo, J. M. \& Matthews, R. G. (1994). The leucine-responsive regulatory protein, a global regulator of metabolism in Escherichia coli. Microbiol Rev 58, 466-490.

Casadaban, M. J., Chou, J. \& Cohen, S. N. (1980). In vitro gene fusions that join an enzymatically active $\beta$-galactosidase segment to amino-terminal fragments of exogenous proteins: Escherichia coli plasmid vectors for the detection and cloning of translation initiation signals. J Bacteriol 143, 971-980.

Fried, M. \& Crothers, D. M. (1981). Equilibria and kinetics of lac repressor-operator interactions by polyacrylamide gel electrophoresis. Nucleic Acids Res 9, 6505-6525.

Garner, M. N. \& Revzin, A. (1981). A gel electrophoresis method for quantifying the binding of proteins to specific DNA regions: application to components of the Escherichia coli lactose operon regulatory system. Nucleic Acids Res 9, 3047-3060.

Ghrist, A. C. \& Stauffer, G. V. (1995). Characterization of the Escherichia coli gcvR gene encoding a negative regulator of $g c v$ expression. J Bacteriol 177, 4980-4984.

Jourdan, A. D. \& Stauffer, G. V. (1998). Mutational analysis of the transcriptional regulator GcvA: amino acids important for activation, repression, and DNA binding. J Bacteriol $\mathbf{1 8 0}$, 4865-4871.

Kahn, M., Kolter, R., Thomas, C., Figurski, D., Meyer, R., Remaut, E. \& Helinski, D. R. (1979). Plasmid cloning vehicles derived from plasmids ColE1, F, R6K, and RK2. Methods Enzymol 68, 268-280.

Kikuchi, G. (1973). The glycine cleavage system: composition, reaction mechanism, and physiological significance. Mol Cell Biochem 1, 169-187.

Kilstrup, M., Meng, L. M., Neuhard, J. \& Nygaard, P. (1989).
Genetic evidence for a repressor of synthesis of cytosine deaminase and purine biosynthesis enzymes in Escherichia coli. J Bacteriol 171, 2124-2127.

Lin, R., D'Ari, R. \& Newman, E. B. (1992). $\lambda$ placMu insertions in genes of the leucine regulon: extension of the regulon to genes not regulated by leucine. J Bacteriol 174, 1948-1955.

Miller, J. H. (1992). A Short Course in Bacterial Genetics. Cold Spring Harbor, NY: Cold Spring Harbor Laboratory.

Mudd, S. H. \& Cantoni, G. L. (1964). Biological transmethylation, methyl-group neogenesis and other 'one-carbon' metabolic reactions dependent upon tetrahydrofolic acid. In Comprehensive Biochemistry, pp. 1-47. Edited by M. M. Florkin \& E. H. Stotz. Amsterdam: Elsevier.

Newman, E. B., D'Ari, R. \& Lin, R. T. (1992). The leucine-Lrp regulon in $E$. coli: a global response in search of a raison d'etre. Cell 68, 617-619.

Panasenko, S. M., Cameron, J. R., Davis, R. W. \& Lehman, I. R. (1977). Five hundred-fold overproduction of DNA ligase after induction of a hybrid lambda lysogen constructed in vitro. Science 196, 188-189.

Plamann, M. D., Rapp, W. D. \& Stauffer, G. V. (1983). Escherichia coli $\mathrm{K} 12$ mutants defective in the glycine cleavage enzyme system. Mol Gen Genet 192, 15-20.

Record, M. T., Jr, Reznikoff, W. S., Craig, M. L., McQuade, K. L. \& Schlax, P. J. (1996). Escherichia coli RNA polymerase $\left(\mathrm{E} \sigma^{70}\right)$, promoters, and the kinetics of the steps of transcription initiation. In Escherichia coli and Salmonella: Cellular and Molecular Biology, pp. 792-821. Edited by F. C. Neidhardt, R. Curtiss III, J. L. Ingraham, E. C. C. Lin, K. B. Low, B. Magasanik, W. Reznikoff, M. Riley, M. Schaechter \& H. E. Umbarger. Washington, DC: American Society for Microbiology.

Rolfes, R. J. \& Zalkin, H. (1988). Regulation of Escherichia coli purF. J Biol Chem 263, 19649-19652.

Sambrook, J., Fritsch, E. F. \& Maniatis, T. (1989). Molecular Cloning: a Laboratory Manual, 2nd edn. Cold Spring Harbor, NY: Cold Spring Harbor Laboratory.

Sarkar, G. \& Sommer, S. (1990). The 'megaprimer' method of sitedirected mutagenesis. Biotechniques 8, 404-407.

Schell, M. A. (1993). Molecular biology of the LysR family of transcriptional regulators. Annu Rev Microbiol 47, 596-626.

Shimada, K., Weisberg, R. A. \& Gottesman, M. E. (1972). Prophage $\lambda$ at unusual chromosomal locations. I. Location of the secondary attachment sites and properties of the lysogens. J Mol Biol 63, 483-503.

Stauffer, G. V., Fogarty, S. \& Stauffer, L. T. (1994). Characterization of the Escherichia coli gcv operon. Gene 142, 17-22.

Stauffer, L. T. \& Stauffer, G. V. (1994). Characterization of the $g c v$ control region from Escherichia coli. J Bacteriol 176, 6159-6164.

Stauffer, L. T. \& Stauffer, G. V. (1999). Role for the leucineresponsive regulatory protein ( $\operatorname{Lrp}$ ) as a structural protein in regulating the Escherichia coli gcvTHP operon. Microbiology $145,569-576$.

Steiert, P. S., Stauffer, L. T. \& Stauffer, G. V. (1990). The lpd gene product functions as the $\mathrm{L}$ protein in the Escherichia coli glycine cleavage enzyme system. J Bacteriol 172, 6142-6144.

Urbanowski, M. L. \& Stauffer, G. V. (1986). Autoregulation by tandem promoters of the Salmonella typhimurium LT2 metJ gene. J Bacteriol 165, 740-745.

Vogel, H. J. \& Bonner, D. M. (1956). Acetylornithinase of Escherichia coli: partial purification and some properties. J Biol Chem 218, 97-106. 
Wilson, R. L. \& Stauffer, G. V. (1994). DNA sequence and characterization of GevA, a LysR family regulatory protein for the Escherichia coli glycine cleavage enzyme system. J Bacteriol 176, 2862-2868.

Wilson, R. L., Stauffer, L. T. \& Stauffer, G. V. (1993a). Roles of the GovA and PurR proteins in negative regulation of the Escherichia coli glycine cleavage enzyme system. J Bacteriol 175, 5129-5134.

Wilson, R. L., Steiert, P. S. \& Stauffer, G. V. (1993b). Positive regulation of the Escherichia coli glycine cleavage enzyme system. J Bacteriol 175, 902-904.
Wilson, R. L., Urbanowski, M. L. \& Stauffer, G. V. (1995). DNA binding sites of the LysR-type regulator GcvA in the $g c v$ and $g c v A$ control regions of Escherichia coli. J Bacteriol 177, 4940-4946.

Zhou, Y., Zhang, X. \& Ebright, R. H. (1991). Random mutagenesis of gene-sized DNA molecules by use of PCR with Taq DNA polymerase. Nucleic Acids Res 19, 6052.

Received 18 December 1998; revised 9 April 1999; accepted 21 April 1999. 